\title{
Osteogenesis and Mineralization of Mesenchymal Stem Cells in Collagen Type I Based Recombinant Peptide Scaffolds
}

Kendell M. Pawelec ${ }^{a 1}$, Davide Confalonieri ${ }^{b}$, Franziska Ehlicke ${ }^{c}$, Huibert A. van Boxtel ${ }^{a}$, Heike Walles ${ }^{b, c}$, Sebastiaan G.J.M. Kluijtmans ${ }^{\mathrm{a}}$

${ }^{a}$ FUJIFILM Manufacturing Europe B.V., Oudenstaart 1, Tilburg, Netherlands

${ }^{\text {b } T r a n s l a t i o n a l ~ C e n t e r ~ W u e r z b u r g ~ ' R e g e n e r a t i v e ~ T h e r a p i e s ~ i n ~ O n c o l o g y ~ a n d ~ M u s c u l o s k e l e t a l ~ D i s e a s e ', ~}$ Wuerzburg, Germany

'University Hospital Wuerzburg, Department Tissue Engineering and Regenerative Medicine (TERM), Wuerzburg, Germany

('Present address: University of Michigan, 2350 Hayward, Ann Arbor, MI 48109, USA)

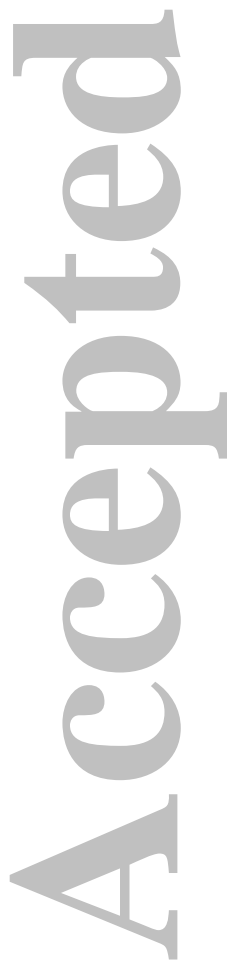

This is the author manuscript accepted for publication and has undergone full peer review but has not been through the copyediting, typesetting, pagination and proofreading process, which may lead to differences between this version and the Version record. Please cite this article as doi:10.1002/ jbm.a.36049. 
Osteogenesis and Mineralization

Recombinant peptides have the power to harness the inherent biocompatibility of natural macromolecules, while maintaining a defined chemistry for use in tissue engineering. Creating scaffolds from peptides requires stabilization via cross-linking, a process known to alter both mechanics and density of adhesion ligands. The chemistry and mechanics of linear scaffolds from a recombinant peptide based on human collagen type I (RCP) was investigated after cross-linking. Three treatments were compared: dehydrothermal treatment (DHT), hexamethylene diisocyanate (HMDIC), and genipin. With crosslinking, mechanical properties were not significantly altered, ranging from $1.9-2.7 \mathrm{kPa}$. However, the chemistry of the scaffolds was changed, affecting properties such as water uptake, and initial adhesion of human mesenchymal stem cells (hMSCs). Genipin cross-linking supported the lowest adhesion, especially during osteoblastic differentiation. While significantly altered, RCP scaffold chemistry did not affect osteoblastic differentiation of hMSCs. After four weeks in vitro, all scaffolds showed excellent cellular infiltration, with up-regulated osteogenic markers (RUNX2, Osteocalcin, Collagen type I) and mineralization, regardless of the cross-linker. Thus, it appears that, without significant changes to mechanical properties, cross-linking chemistry did not regulate hMSC differentiation on scaffolds from recombinant peptides, a growing class of materials with the ability to expand the horizons of regenerative medicine.

Keywords: recombinant collagen, stem cells, osteogenesis, differentiation, cross-linking

\section{Introduction}

Reconstruction of musculoskeletal injuries after trauma remains a challenge for current regenerative medicine technologies. Bone repair, in particular, is problematic due to the biological and mechanical demands at the site of trauma. As one of the key tools in regenerative medicine, porous scaffolds allow cellular infiltration and nutrient diffusion, and can be tailored to elicit an appropriate biological response. Scaffolds have been fabricated from a variety of materials, including ceramics and polymers.

John Wiley \& Sons, Inc.

This article is protected by copyright. All rights reserved. 
Osteogenesis and Mineralization

One of the leading biological polymers is collagen type I, the major component of the extracellular matrix (ECM) in bone [1]. However, concerns have been raised regarding immunogenicity and batch-tobatch variation of this animal derived protein when used in biomedical devices [2]. An attractive alternative are recombinant polymers, which retain the native biocompatibility of the template, but have a defined chemistry, without immunogenic concerns. Like collagen scaffolds, recombinant peptides can be formed into porous, interconnected scaffolds, with tunable properties. In this study we have used a recombinant peptide based on human collagen type I (RCP, Cellnest ${ }^{\mathrm{TM}}$ ), which is enriched with cell binding RGD motives.

Cellular response to environmental cues is mediated through cell adhesion receptors. Integrin binding, for example, is responsible for stem cell differentiation in response to mechanics, one of the most important environmental stimuli in bone [3]. On two-dimensional (2D) substrates, mechanical stiffness of over $25 \mathrm{kPa}$ can lead to spontaneous osteoblastic differentiation [4]. Within three-dimensional (3D) systems, however, the mechanical values required for osteogenesis are markedly different. In hydrogel systems, stiffness of only $11 \mathrm{kPa}$ have been reported to up-regulate osteoblastic markers [3, 5]. Even values as low as 1-2 kPa have been shown to affect the gene expression of stem cells in collagen scaffolds [6]. Thus, while it is known that mechanics are important for directing stem cell fate, different material systems have yielded a range of thresholds which can support spontaneous osteogenic differentiation.

Mechanical properties and stabilization of scaffold structures are critical to supporting cell adhesion and growth, and are often achieved through cross-linking reactions. However, cross-linking alters, not only the mechanical properties of scaffolds, but it has a strong effect on scaffold chemistry, as well [7]. Crosslinkers which are incorporated into the scaffold structure, such as glutaraldehyde, can exhibit cytotoxic

John Wiley \& Sons, Inc.

This article is protected by copyright. All rights reserved. 
Osteogenesis and Mineralization

effects as the chemical is released during degradation [8]. In contrast, cross-linking methods such as dehydrothermal treatment rely on elevated temperatures to allow condensation reactions to occur along the peptide. Without the addition of a chemical, there are no potentially toxic side products introduced. However, beneficial mechanical stabilization must be balanced with the degradation reactions which can occur simultaneously at high temperatures and longer cross-linking times [9]. The result of chemical changes to the scaffold also affect cellular response, independently of mechanical properties $[7,10]$. Cross-linking often disrupts cell adhesion ligands, leading to reduced adhesion and cell growth [10].

To best utilize the beneficial aspects of recombinant peptides, there is still a need for characterization of cellular response on this emerging class of biomaterials. This study examined the role of cross-linking on the osteogenic differentiation and mineralization capability of human mesenchymal stem cells (hMSCs) within RCP scaffolds. It was hypothesized that changes in the mechanical and chemical properties of the scaffolds, with cross-linking, would affect the cellular response. Three cross-linking methods were chosen: dehydrothermal treatment (DHT), hexamethylene diisocyanate (HMDIC), and genipin. DHT cross-linking links carboxyl and amine groups, while HMDIC and genipin are two chemical cross-linkers which link amine groups and are incorporated into the structure of the scaffold [11, 12]. The scaffold properties were characterized based on their mechanics and interaction with the aqueous environment. The biological response of RCP scaffolds was verified by demonstrating their ability to support hMSC proliferation and osteoblastic differentiation, paving the way for further uses of recombinant peptides in regenerative medicine.

2. Materials and Methods

2.1 Scaffold Production

John Wiley \& Sons, Inc.

This article is protected by copyright. All rights reserved. 
Osteogenesis and Mineralization

Unless noted, all reagents came from Sigma Aldrich. Scaffolds were made from a recombinant peptide based on human collagen type I (RCP, Cellnest ${ }^{\mathrm{TM}}$, Fujifilm). RCP is enriched with RGD groups along the peptide chain, which has a uniform mass of $51 \mathrm{kDa}$. On cooling, RCP chains form a network resembling natural gelatin. Thus, unlike collagen type I, it does not have the highly organized triple-helices which make RGD groups inaccessible for cell binding $[7,13]$. A solution of $7.5 \mathrm{wt} \% \mathrm{RCP}$ was prepared in distilled water at $50^{\circ} \mathrm{C}$, and degassed. Linear scaffolds were produced via a directional ice-templating technique which relies on a controlled bath temperature to form the ice $[14,15]$. A solution consisting of 7.5 wt\% RCP and 1 wt\% ethanol was added to a polytetrafluoroethylene (PTFE) coated aluminum mold. The solution was gelled for $20 \mathrm{~min}$ at $10^{\circ} \mathrm{C}$. The bath temperature was adjusted to $-30^{\circ} \mathrm{C}$ and held for 10 sec to nucleate ice at the mold base. The temperature was immediately adjusted to $-4^{\circ} \mathrm{C}$, and subsequently cooled with a slope of $-0.1^{\circ} \mathrm{C} / \mathrm{min}$ over the remainder of the freezing protocol. Ice growth was complete after 90 minutes and scaffolds were immediately lyophyilized in a Zirbus freeze drier for $24 \mathrm{~h}$ at $-15^{\circ} \mathrm{C}$, below 8-12 Pa. Secondary drying was completed for $10 \mathrm{~h}$ at $25^{\circ} \mathrm{C}$. Scaffolds were stored at room temperature prior to use.

Prior to cross-linking, linear scaffolds, from $7.5 \mathrm{wt} \% \mathrm{RCP}$, were cut into disks with a size of $5 \mathrm{~mm}$ in diameter, $2 \mathrm{~mm}$ thick. Three cross-linking methods were compared: dehydrothermal treatment (DHT), hexamethylene diisocyanate (HMDIC) and genipin. For DHT treatment, scaffolds were first dried at $60^{\circ} \mathrm{C}$, under vacuum, overnight. Cross-linking was done at $160^{\circ} \mathrm{C}$ (relating to an actual sample temperature of $150^{\circ} \mathrm{C}$ ), under a vacuum of less than $1 \times 10^{-2} \mathrm{mbar}$, for $24 \mathrm{~h}$. This method was adapted from literature protocols, where temperatures range from $105-180^{\circ} \mathrm{C}$, and the time varies between $24-96 \mathrm{~h}$ [16-18]. Given the demands of the biological testing, 4 weeks in a physiological environment, a strong crosslinking protocol was deemed necessary. With a pressure below $4 \times 10^{-2} \mathrm{mbar}$, treatment at $160^{\circ} \mathrm{C}$, for 24 h, could be completed without degradation, as shown by mass spectrometry analyses of a trypsin digest,

John Wiley \& Sons, Inc.

This article is protected by copyright. All rights reserved. 
Osteogenesis and Mineralization

which had no unidentified fragments; in addition the amino acid content did not vary significantly before and after cross-linking. HMDIC cross-linking was completed in 96.5 vol\% ethanol with 0.025 grams HMDIC per gram RCP scaffold, in a sealed container. The volume of cross-linking solution was kept constant at 20 times the mass of the RCP. The scaffolds were rotated, at room temperature, at 250 rpm for $24 \mathrm{~h}$. Scaffolds were then washed three times in 100\% ethanol, 10 min each. After excess ethanol was removed, the samples were dried overnight, at $60^{\circ} \mathrm{C}$. Genipin cross-linking was done with a solution of $0.125 \%(\mathrm{w} / \mathrm{v})$ genipin in $90 \%$ ethanol at room temperature. Enough cross-linking solution was added to a beaker to completely cover the scaffold, sealed with Parafilm, and holes were punched in the top, to allow oxygen diffusion. After 48 hours, when the reaction was complete, the scaffolds had changed color, becoming a dark blue. Scaffolds were then washed three times in $100 \%$ ethanol and allowed to dry at $60^{\circ} \mathrm{C}$, overnight.

\subsection{Scaffold Characterization}

Scaffolds were imaged via both scanning electron microscopy (SEM) and micro-computed tomography $(\mu \mathrm{CT})$. For SEM, scaffolds were cut with a razor blade and sputter coated with platinum. Prior to imaging, samples with cells were gently washed in 1x PBS twice and fixed in 3.7\% paraformaldehyde for 15 min.

Scaffolds were then incubated in graded ethanol dilutions, at room temperature, for $1 \mathrm{~h}$ each: 70\%, $80 \%, 90 \%$, and $100 \%$ ethanol. Finally, the scaffolds were washed for $10 \mathrm{~min}$ in hexamethyldisilizane (HMDS) and allowed to dry overnight in a fume hood. Imaging was done using a Jeol JSM-6335F Field Emission Scanning Electron Microscope at an accelerating voltage of $5 \mathrm{keV}$.

The pore size of the scaffolds was evaluated using SEM micrographs. Pore diameter was quantified perpendicular to the aligned structure (Image J software). The final measurement was a result of at least 10 regions within the scaffolds and verified via three-dimensional reconstructions via $\mu \mathrm{CT}$. Threedimensional views were taken using a Skyscan $1172 \mu \mathrm{CT}$ (Bruker). Scaffolds of $5 \mathrm{~mm}$ in diameter were

John Wiley \& Sons, Inc.

This article is protected by copyright. All rights reserved. 
Osteogenesis and Mineralization

imaged at $35 \mathrm{keV}, 5 \mathrm{~W}$, with a resolution of $1.5 \mu \mathrm{m}$. Reconstructions were performed on Skyscan software and 3D images were made using Image J software.

DHT and HMDIC cross-linked samples were evaluated by measuring the available lysines before and after cross-linking, using a TNBS-assay. Genipin samples were not tested due to interference from the blue color, formed during cross-linking. Native RCP and cross-linked scaffold (5 mg) was incubated at $37^{\circ} \mathrm{C}$ for $3 \mathrm{~h}$ with $0.5 \mathrm{ml}$ of a $4 \%(\mathrm{w} / \mathrm{v})$ sodium bicarbonate solution and $1 \mathrm{ml}$ of a $1 \%(\mathrm{w} / \mathrm{v}) 2,4,6-$ trinitrobenzenesulfonic acid aqueous solution (TNBS). The material was then hydrolyzed at $37^{\circ} \mathrm{C}$ overnight, after adding $5 \mathrm{ml}$ of concentrated hydrochloric acid (37\%) and $2.5 \mathrm{ml}$ of water. The final solution weight was raised to $12.5 \mathrm{~g}$ with water for all samples. Absorbance was read at $345 \mathrm{~nm}$ in a UV/Vis spectrophotometer (CARY100), after a 10-fold dilution by weight, and was measured with respect to a blank. The native RCP control was known to have a primary amine density (concentration) of 34 moles per mole RCP (33 lysine and a terminal glycine [19]). These primary amines react quickly with TNBS to form TNP- $\varepsilon$-Lysine and TNP- $\alpha$-Glycine, with molar extinction coefficients of $1.41 \times 10^{4}$ and $1.25 \times 10^{4} \mathrm{M} / \mathrm{cm}$, respectively in a $0.48 \mathrm{M}$ hydrochloric acid solution. Thus, cross-linking degree was calculated from the concentration of uncross-linked native $R C P$, before $\left([R C P]_{b}\right)$ and after $\left([R C P]_{a}\right)$ crosslinking, using the following relation:

cross-linking degree $(\%)=\left([R C P]_{b}-[R C P]_{a} /[R C P]_{b}\right) * 100 \%$

The mechanical properties of the cross-linked scaffolds were tested in uniaxial compression, so that the direction of force was parallel to the long axis of the pores $(n=5)$. Prior to testing, scaffolds were hydrated overnight at room temperature in phosphate buffered saline (PBS) with $0.01 \%$ sodium azide, and air was removed under vacuum. Just prior to testing, scaffold dimensions were measured using calipers for accurate stress calculations. The hydrated scaffolds were then placed between the plates of

John Wiley \& Sons, Inc.

This article is protected by copyright. All rights reserved. 
Osteogenesis and Mineralization

the dynamic mechanical analysis (DMA) machine (TA Instruments, Q800) and a controlled force test was conducted: $0-15 \mathrm{~N}$ force with a rate of $0.5 \mathrm{~N} / \mathrm{min}$. The stress-strain data recorded during the tests was used to determine the yield stress and the Young's modulus. The Young's modulus was measured using the slope of the tangent to the elastic region of the curve (initial linear portion). Where the tangent line, with a $0.2 \%$ strain off-set, intersected the curve, the stress value was taken to be the yield stress.

\subsection{Hydration and Water Up-take}

The ability of the scaffolds to interact with water was tested via both water up-take and overall hydration. Scaffolds, of the same size as those tested in vitro, $5 \mathrm{~mm}$ diameter and $2 \mathrm{~mm}$ height, were weighed in the dry state, after cross-linking. To gain values representative of the in vitro culture situation, the scaffolds were hydrated by autoclaving, Section 2.5. Scaffolds were removed from the PBS and weighed directly. This measure was called the overall hydration, which correlated to the total amount of water which could be captured by the scaffold structure. The scaffold was then placed on filter paper (Whatmann) and the water was pressed out, under firm pressure, before weighing the scaffold again. This measure was defined as water up-take, as this was the water which was incorporated in the RCP solid structure by swelling. Both measures were the average of three samples, and were calculated as the percent of mass change from the dry scaffolds:

Hydration $(\%)=100 \times\left(\right.$ mass $_{\text {wet }}-$ mass $\left._{\text {dry }}\right) /$ mass $_{\text {dry }}$

\subsection{Human Mesenchymal Stem Cells}

Human mesenchymal stem cells (hMSCs) were isolated from bone marrow, from the femur head of osteoarthritic patients undergoing hip replacement, but otherwise healthy. The procedure was performed under the approval of the Local Ethics Committee of the University of Wuerzburg and informed consent from the patients ( 2 females; mean donor age: $65 \pm 5$, range: 61 - 71 years).

John Wiley \& Sons, Inc.

This article is protected by copyright. All rights reserved. 
Osteogenesis and Mineralization

hMSCs were isolated following the plastic adherence criteria. Briefly, the trabecular bone was removed from the femur heads and washed in DMEM/F12. The solution was centrifuged for $5 \mathrm{~min}$ at $270 \mathrm{~g}$ and the cells were extracted from the remaining bone through vigorous shaking. The cells were reseeded at the final concentration of 1 million cells $/ 175 \mathrm{~cm}^{2}$ T-Flask in fully supplemented medium (1:1 DMEM/Ham F12 with L-glutamine (Gibco, Life Technologies), 10\% FCS (Lonza), 1\% penicillin/streptomycin (Pen/Strep, Gibco, Invitrogen), $50 \mu \mathrm{g} / \mathrm{ml}$ ascorbate-2-phosphate). Culture medium was changed 3 times a week, starting from day 4, after washing the plates twice with Dulbecco's PBS (DPBS, Gibco, Life Technologies). The hMSCs were expanded, at $37^{\circ} \mathrm{C}$ in a humidified atmosphere of $5 \% \mathrm{CO}_{2}$, in growth medium: MSCGMCD medium (Lonza), 2\% FCS (Lonza), and 1\% Pen/Strep. Culture medium was replaced 3 times a week

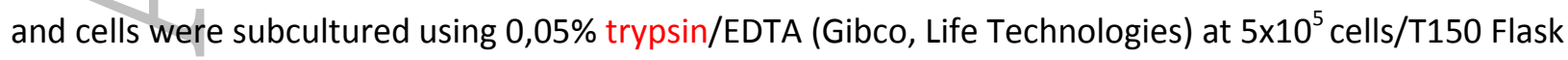
after reaching $80 \%$ confluence. hMSCs between passage 2 and 4 were used for the experiments.

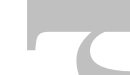

hMSC characterization was performed on cells from passage 2-3 via flow cytometry analysis of surface markers, according to established protocols. The cells were resuspended in DPBS supplemented with $2 \%$ FCS and stained, for $30 \mathrm{~min}$, at $4^{\circ} \mathrm{C}$ with the following antibodies: anti-human CD90-PE (clone MOPC-21; BD Pharmingen), CD29-PE (clone WM59, BD Pharmingen), CD44-FITC (clone G44-26; BD Pharmingen), CD45-PE (clone J33; Beckman Coulter), CD73-PE (clone 55-7H1, BD Pharmingen), CD14-FITC (clone 61D3, eBioscience), and CD105-PE (clone 266, BD Pharmingen). Appropriate isotype controls were included, using either antihuman IgG1-PE (clone 679.1Mc7, Beckman Coulter) or antihuman IgG1-FITC (clone 679.1MC7, Beckman Coulter). Stained cells were washed with DPBS 2\% FCS and analyzed for flow cytometry. Analyses were performed on a FACSCalibur (BD Biosciences, Franklin Lakes, NJ) collecting at least 10,000 events.

John Wiley \& Sons, Inc.

This article is protected by copyright. All rights reserved. 
Osteogenesis and Mineralization

Differentiation to adipogenic, osteogenic, and chondrogenic lineages was also evaluated. For adipogenic and osteogenic differentiation, 50,000 cells/well were seeded in 4-well Permanox chamberslides (NuncTM, Thermo Fisher Scientific) in a differentiation medium. Adipogenic media consisted of DMEM High glucose (Gibco, Life Technologies), 10\% FCS , 500 $\mu$ M IBMX (AppliChem), $1 \mu \mathrm{g} / \mathrm{ml}$ insulin, $100 \mu \mathrm{M}$ indomethacin and $1 \mu \mathrm{M}$ dexamethasone supplemented with 1\% Pen/Strep; osteogenic media was DMEM High glucose, $10 \% \mathrm{FCS}, 1 \times 10^{-7} \mathrm{M}$ dexamethasone, $10 \mathrm{mM} \beta$-glycerophosphate and $50 \mu \mathrm{g} / \mathrm{ml}$ ascorbate-2-phosphate, and 1\% Pen/Strep. The differentiation medium was changed every 2-3 days for 14 days (adipogenic differentiation) or 28 days (osteogenic differentiation). At day 14, the adipogenic differentiation was evaluated by staining the intracellular lipid droplets with Oil Red O. At day 28, osteogenic differentiation was evaluated by staining the deposited mineral matrix with Alizarin Red S. hMSCs from all the patients deposited significant amount of mineral components at the selected passages when compared to negative controls. For chondrogenic differentiation, 250,000 cells were seeded into $15 \mathrm{ml}$ centrifuge tubes and allowed to form a cell pellet after centrifugation (5 min, $270 \mathrm{~g}$ ). The cell pellets were cultured overnight at $37^{\circ} \mathrm{C}$ in MSCGM-CD medium and were transferred to 24-well plates the following day. The medium was then changed to a chondrogenic medium consisting of DMEM High glucose, $100 \mu \mathrm{g} / \mathrm{ml} \mathrm{Na}^{2+}$ pyruvate, $40 \mu \mathrm{g} / \mathrm{ml}$ L-proline, 0.01\% v/v ITS-1 (BD Bioscences), $10 \mathrm{ng} / \mathrm{ml}$ TGF-beta 3 (R\&D Systems), 50 mg/ml ascorbate-2-phosphate and 100nM dexamethasone, supplemented with $1 \%$ Pen/Strep. The differentiation medium was changed every 3-4 days, for 21 days. At day 21 chondrogenic differentiation was evaluated by embedding the cell pellets in paraffin, using standard established procedures, and staining $5 \mu \mathrm{m}$ thick slices of the samples with Alician Blue staining of the glycosaminoglycans deposited in the extracellular matrix. hMSCs preserved the ability to differentiate into all three lineages.

\subsection{Differentiation Study}

John Wiley \& Sons, Inc.

This article is protected by copyright. All rights reserved. 
Osteogenesis and Mineralization

Scaffolds ( $5 \mathrm{~mm}$ in diameter, $2 \mathrm{~mm}$ thick) were sterilized and hydrated by autoclaving in DPBS at $121^{\circ} \mathrm{C}$ for $20 \mathrm{~min}$, and incubated in growth media overnight. hMSCs were seeded onto scaffolds via dynamic seeding $(n=3)$. Scaffolds were placed in $50 \mathrm{ml}$ centrifuge tubes with a cell suspension of $1 \times 10^{5}$ cells/scaffold $\left(5 \times 10^{5}\right.$ cells $\left./ \mathrm{ml}\right)$ in growth media. The cells and scaffolds were gently rotated for $4 \mathrm{~h}$ at $37^{\circ} \mathrm{C}$, at $250 \mathrm{rpm}$. After seeding, the scaffolds were removed and placed in individual wells of a tissue culture plate. Scaffolds were cultured in static conditions, either in growth media or osteogenic media for a total of 4 weeks in 48 well, low attachment polystyrene plates. Media was changed every 3-4 days. The study was performed independently with cells from 2 individuals.

\subsection{Proliferation}

Proliferation was measured via DNA quantification, using Quant-iTTM PicoGreen ds DNA Reagent (Invitrogen). Scaffolds were washed in DPBS before freezing at $-80^{\circ} \mathrm{C}$, for at least $6 \mathrm{~h}$. As controls, scaffolds without cells were harvested. Prior to measurement, scaffolds were degraded overnight in 300 $\mu l$ papain buffer $(5 \mathrm{U} / \mathrm{ml})$ at $60^{\circ} \mathrm{C}$. A standard curve was created at the initial cell seeding to estimate final cell number. The assay was performed according to the manufacturer's instructions. Briefly, samples were pipetted into a black 96 well plate, with standard curves and cell free controls. After adding the pico-green dye (1:200), the fluorescence was read at excitation $480 \mathrm{~nm}$, emission $520 \mathrm{~nm}$. Measurements were taken on day 1 to calculate initial cell adhesion, then further on days 7, 14, 21, and 28 , and are reported as the average of all samples ( 2 individuals) with standard error.

\subsection{Polymerase Chain Reaction}

For RNA isolation, Direct-zol RNA Mini Prep columns were used (Direct-zol, cat no. R2050). Briefly, scaffolds were homogenized in trizol before proceeding with the on-column isolation, according to the manufacturer's instructions, including an on-column DNase step. Quantification of RNA was performed by placing $2 \mu$ l of RNA into a NanoQuant Plate, after blanking with pure water, using a fluorescent reader (TECAN Infinite M200). cDNA was obtained using the BioRad iScript cDNA Synthesis kit.

John Wiley \& Sons, Inc.

This article is protected by copyright. All rights reserved. 
Osteogenesis and Mineralization

Quantitative real-time Polymerase Chain Reaction (qPCR) was performed on a BioRad CFX96 Real Time System (C1000 Thermal Cycler), using SSo Fast Eva Green (BioRad). Genes for osteoblastic differentiation and mineralization were examined: BMP2, RUNX2, alkaline phosphatase (ALP), osteocalcin, osteonectin and collagen type I, and one chondrocytic differentiation marker, collagen type II, as a control. GAPDH was used as the housekeeping gene. mRNA expression levels are normalized to cells cultured with proliferation medium in DHT scaffolds at day 7. All results are reported as an average of all samples (2 individuals) with standard error.

\subsection{Mineral Content}

The kit Osteolmage ${ }^{\mathrm{TM}}$ Mineralization Assay (Lonza, \#PA1503) was used to quantify the formation of hydroxyapatite (HA) within the samples, as the kit is specific for $\mathrm{HA}$, rather than generic calcium phosphates. The manufacturer's instructions were adapted for use with scaffolds as follows. Samples were washed once in phosphate buffered saline (PBS) and transferred into wells of a black 96 well plate. The samples were then fixed in 3.7\% paraformaldehyde for 15 min and washed once in Wash Buffer (provided by the kit). Staining reagent was incubated for $30 \mathrm{~min}$ with the scaffolds, and, after 3 washes, the fluorescence was read at excitation/emission of 492/520 nm (TECAN Infinite M200). The change in mineral content was calculated as the difference between day 14 and day 28 measurements. Mineral content in osteogenic scaffolds is reported as the fold change from the mineral content in growth media.

\subsection{Immunohistochemical Staining}

Immunohistochemical staining was performed with a confocal microscope (Leica TCS SP8 software: LAS X). Scaffolds were washed gently in PBS, then fixed for $15 \mathrm{~min}$ in $3.7 \%$ paraformaldehyde and stored at $4^{\circ} \mathrm{C}$ in PBS prior to staining. Samples were hydrated in PBS+0.5\% tween-20 (PBST) for 5 min and then permeabilized in $0.2 \%$ triton X-100, followed by a PBST wash. Blocking was done in $5 \%$ goat serum in PBS for 20 min at room temperature. Rabbit primary antibodies for actin (Abcam ab1801) and collagen

John Wiley \& Sons, Inc.

This article is protected by copyright. All rights reserved. 
Osteogenesis and Mineralization

type I (Axcris Antibodies BP8028) were used at 1:200 dilution in PBS. Only one antibody was used per sample. Incubation with primary antibodies was performed for $60 \mathrm{~min}$ at room temperature, followed by 3 PBST washes. Anti-goat secondary antibodies (AlexaFlour 647 and AlexaFluor 488) were diluted in PBST (1:1000) and incubated with samples for $60 \mathrm{~min}$ at room temperature, in the dark. Three washes with PBST followed. Finally, the cell nuclei were stained with DAPI (1:1000 in PBST) for 5 min.

\subsection{Statistics}

All statistics were done using GraphPad Prism software using ANOVA and a post-hoc Tukey test. A confidence interval of $95 \%$ was reported in all cases. Significance is indicated on the graphs.

3 Results

\subsection{Scaffold Properties}

The scaffolds were composed of linear channels with a mean pore size of 350 - $430 \mu \mathrm{m}$, Figure 1 . The cross-linking reactions were successful, with DHT and HMDIC reaching $28.6 \pm 6.5$ and $52.7 \pm 0.8 \%$ of the maximum cross-linking density. This corresponded to $42.2 \pm 3.8 \mathrm{mmol}$ lysine per gram RCP remaining after DHT, approximately $9.7 \pm 2.2$ cross-links per RCP chain, compared to $28.0 \pm 0.5$ mmol lysine per gram RCP after HMDIC cross-linking, roughly $9.0 \pm 0.1$ crosslinks per RCP chain. However, it is not known what fraction of these linkages are intramolecular and what is intermolecular. Genipin could not be tested directly due to the interference of the blue color.

Given the difference in cross-linking chemistry, it was hypothesized that cross-linking could alter the physical properties of the RCP scaffolds, Table 1. In general the compressive modulus increased from 1.9 \pm 0.3 for $\mathrm{DHT}$ to $2.7 \pm 0.6$ for genipin cross-linking. The highest yield stress, $17.3 \mathrm{kPa}$, occurred with HMDIC scaffolds. HMDIC and genipin scaffolds had a significantly higher overall hydration than DHT cross-linked. However, HMDIC had significantly lower water up-take, or water bound to the scaffold structure, with only $131 \%$ compared to 188 or $175 \%$ for DHT or genipin, respectively.

John Wiley \& Sons, Inc.

This article is protected by copyright. All rights reserved. 
Osteogenesis and Mineralization

\subsection{Attachment and Proliferation}

Linear scaffolds were chosen to allow the maximum cellular penetration through the structure. Indeed, after 28 days in vitro culture, hMSCs were visible throughout the scaffold pores, Figure 2, regardless of the cross-linker or media type. Initial cell attachment to the scaffolds was high, consistently around $50 \%$ in growth media, regardless of the cross-linking, Figure 2(g). In osteogenic media, the attachment tended to decrease. On genipin scaffolds, in particular, attachment dropped significantly to $22 \%$.

Proliferation, in both the growth and osteogenic media, leveled off between 14 and 21 days. Cells in growth media had a significantly higher cell proliferation than those in osteogenic media, Figure 2(h).

There were no significant differences between the proliferation of cells after 28 days, despite differences in cross-linking.

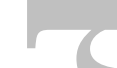

\subsection{Osteoblast Differentiation and Mineralization}

Cell response on RCP scaffolds was also evaluated via mRNA levels, which were normalized by the expression of cells on DHT cross-linked scaffolds in growth media (day 7). The expression of the early osteoblast markers BMP2 and RUNX2 was largely determined by the type of media used, Figure 3. BMP2 expression was significantly down-regulated in osteogenic media, at day 7, Figure 3(a). hMSCs in growth media exhibited no markers of differentiation towards a chondrogenic lineage, measured via collagen type II (threshold above the limits of detection in all samples), which is also known to be related to BMP2. Thus, the significantly higher BMP2 expression in growth media was taken to be a basal level for the hMSCs. In contrast to BMP2, RUNX2 was significantly up-regulated in osteogenic media, reaching a peak at day 14, Figure 3(b). Within the first week, during the early stages of differentiation, the hMSCs showed a well spread morphology along the RCP scaffold pore walls, and were able to bridge gaps between the pores. Little difference was observed between the cross-linkers during early

John Wiley \& Sons, Inc.

This article is protected by copyright. All rights reserved. 
Osteogenesis and Mineralization

differentiation. However, genipin scaffolds tended to have the lowest levels of BMP2 and RUNX2 expression overall.

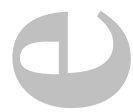

Extracellular matrix (ECM) production was examined as well, as this is an important aspect of building a mineralized network to support bone healing. Collagen type I, a marker for ECM production, was significantly up-regulated in osteogenic media, Figure 4(a). Within the scaffold, the collagen was deposited along the walls of the scaffold. The collagen deposition followed the elongated orientation of the cells, observed via actin staining, Figure 4.

Mineralization is an important aspect of creating a healthy bone tissue, and is the final goal of any bone tissue engineering effort. Markers for mineralization include ALP, osteocalcin and osteonectin, all of which were affected by the media type, Figure 5. A peak in ALP expression was observed around day 14, and was significantly enhanced with osteogenic media at all times through the study. Osteocalcin was also significantly up-regulated by osteogenic media. The greatest increase was observed in DHT crosslinked samples. Osteonectin, which is incorporated into the ECM at a high rate during bone deposition, tended to be up-regulated with osteogenic media [20]. The expression of osteonectin did not significantly vary between the cross-linkers, nor did measurements of the HA content in the scaffolds, Figure 5(a). However, genipin scaffolds demonstrated the greatest variability, of the cross-linkers tested, in promoting a mineralization response.

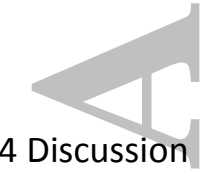

Regenerative medicine is dependent on directing environmental cues to enhance tissue repair. In the case of bone tissue engineering, the biochemical and mechanical environment of scaffolds is particularly important for regulating the final functional outcome. Of the many materials which are available,

John Wiley \& Sons, Inc.

This article is protected by copyright. All rights reserved. 
Osteogenesis and Mineralization

recombinant forms of natural polymers offer the inherent biocompatibility of native tissue without the risks of an immunogenic response and with a reproducible chemistry [2]. Additionally, recombinant polymers can be tuned to incorporate cell signaling moieties, such as the RCP used in the current study, which was enriched with RGD groups. Enhancing the density of cell adhesion ligands is known to alter cellular spreading and differentiation, and thus cell response may be affected by the ligand density within the peptide $[21,22]$. While the cellular environment has been widely investigated in systems of ceramics and polymers, little work has been done to characterize the osteogenic potential of recombinant scaffolds.

Cross-linking plays an important role in the stabilization of scaffold structures, but recently, it has been demonstrated that cross-linking reactions can also remove, or block, ligands important for cell adhesion and attachment [10]. As changes in ligand binding also mediate differentiation, the method of scaffold stabilization requires careful consideration [3]. Therefore, selection of cross-linkers affects not just mechanics, but scaffold chemistry as well, both of which can act to direct cell fate.

\subsection{Cross-linking and Scaffold Properties}

The scaffold structure was kept constant throughout the study, and was not altered by any of the crosslinking methods used. The architecture itself was tailored for bone tissue engineering. The transverse pore size, around $400 \mu \mathrm{m}$, is within the range shown to promote bone in-growth, with linear channels to direct cellular infiltration and mineralization throughout the scaffold $[23,24]$. While the structure did not change, the mechanical properties of scaffolds, and the interaction with the aqueous environment, were investigated, to understand how the interplay between mechanics and chemistry affected osteoblast differentiation of hMSCs.

John Wiley \& Sons, Inc.

This article is protected by copyright. All rights reserved. 
Osteogenesis and Mineralization

In this study, three cross-linkers with varied chemistry were used: DHT, HMDIC, and genipin. These cross-linkers were chosen due to their low cytotoxicity compared to traditional cross-linkers, such as glutaraldehyde $[8,25]$. All cross-linking reactions were effective at stabilizing the RCP scaffolds over the course of the 4 weeks in vitro study. Examining the cross-linking degree, revealed that HMDIC yielded a higher percentage of possible covalent cross-links, compared to the percentage created during DHT cross-linking. However, due to the fact that HMDIC cross-linking relies on two amine groups, the overall number of available cross-links is less than DHT, which is a condensation reaction of carboxyl and amine groups. Thus, the cross-linking degree of $28.6 \%$ for DHT corresponded to an average of 9.7 out of a possible 34 cross-links per RCP molecule, while HMDIC averaged 9.0 cross-links out of a possible 17 . The use of amines in HMDIC cross-linking also meant that significantly fewer lysine residues remained after stabilization when compared to DHT, 28 and $42 \mathrm{mmol}$ for HMDIC and DHT, respectively. Diminished numbers of lysine groups are also expected in genipin cross-linked samples, as genipin also relies on a reaction between two amines [26]. In DHT samples, the loss of a lysine corresponds to a loss of a carboxyl group, which, in theory, can significantly reduce cell adhesion, as carboxyl groups are found in the RGD cell adhesion ligand [10].However, at moderate levels, DHT has been shown to retain integrin ligands within scaffold structure [27]. For this reason, stronger cross-linking was not investigated using the DHT method.

The differences in hydration properties of the RCP structures also suggest that the scaffold chemistry was altered by the various cross-linking reactions taking place. Of the three methods, DHT does not incorporate an exogenous molecule into the structure [9]. Both chemical cross-linkers, HMDIC and genipin, insert a chemical moiety into RCP network. In the case of HMDIC, a linear chain is added and genipin incorporates a ring shaped molecule $[11,12]$. The addition of long chains into gelatin structures is known to increase water absorption and elastic response [26]. Thus, of the three cross-linkers, HMDIC

John Wiley \& Sons, Inc.

This article is protected by copyright. All rights reserved. 
Osteogenesis and Mineralization

had the greatest overall hydration, or total amount of water which could be contained by the scaffold [26]. While the overall hydration was low with DHT cross-linking, a large amount of the water was taken up by the scaffold within the pore walls, measured by water up-take. This may be due to the severe dehydration of the RCP structure under low vacuum conditions, during cross-linking. Alternatively, chemical cross-linkers may have reduced the hydrophilicity of the RCP scaffold with the addition of hydrophobic chains. The observation, that the lowest overall hydration corresponded to the highest water up-take, has been reported previously in collagen scaffolds [28].

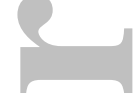

Despite the differences in scaffold hydration, there was no significant difference in the compressive modulus of the hydrated scaffolds. The comparable mechanical properties may be due to the fact that the average number of cross-links per RCP chain was similar in all scaffolds, even if the chemistry, notably the amine content, was altered. In compression, the RCP scaffolds had moduli ranging from 1.9 to $2.7 \mathrm{kPa}$, for $\mathrm{DHT}$ and genipin cross-linking respectively. These values lie within the range of mechanical properties reported in literature for bone tissue engineering scaffolds from biological polymers [29].

\subsection{Osteoblastic Differentiation}

The open structure of the linear scaffolds was designed to allow the maximum diffusion of cells and nutrients throughout the scaffold. The initial attachment of the cells, around $50 \%$, is comparable to attachment on native collagen scaffolds, demonstrating the biocompatibility of the recombinant peptide [23]. The addition of osteogenic media reduced cell attachment on the scaffolds, probably due to an alteration in the cell membrane receptors, which differ between MSCs and osteoblasts [30]. As measurements of attachment were taken after $24 \mathrm{~h}$, it is not expected that different rates of proliferation played a significant role in the attachment. Over the course of 28 days, the cells were able

John Wiley \& Sons, Inc.

This article is protected by copyright. All rights reserved. 
Osteogenesis and Mineralization

to penetrate the entire scaffold volume and fill the pores, illustrating the effectiveness of the linear scaffold for promoting cell growth inside the structure, regardless of cross-linking.

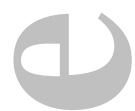

The up-regulation of osteogenic markers, at both the early and late stages of differentiation, confirmed that the RCP scaffolds could support osteogenesis. During the initial stages of differentiation, hMSCs showed increased mRNA expression of RUNX2, which regulates the expression of several downstream proteins, such as collagen type I and osteocalcin [31]. However, hMSCs cultured in growth media, exhibited a statistically higher BMP2 expression than those in osteogenic media, over one week of culture. BMP2 is a potent growth factor in vivo, vital to bone healing, and linked, not only to osteogenesis, but also to chondrogenesis [31, 32]. Administration of BMP2 can lead to an up-regulation of bone formation, a process dependent on the cell type and species of the source $[33,34]$. However, human MSCs have been shown to be unresponsive to BMP2 [34, 35]. To be certain that the BMP2 expression of cells in growth media represented a basal level and was not a marker for chondrogenesis, the expression of collagen type II was evaluated. With no collagen type II expression, it was confirmed that osteogenesis did not rely on BMP2 up-regulation, but on RUNX2.

Osteogenic differentiation and mineralization occurred in all scaffolds with osteogenic media. The upregulation of collagen type I suggested that cells were laying down a collagenous matrix which could then be mineralized [36]. This was confirmed by the significant increase in ALP and osteocalcin. Mineralization of the scaffolds was generally 2 - 3 fold higher on scaffolds with osteogenic media, further confirming that hMSCs were in the process of making bone tissue. The final measure of mineralization was very dependent on the individual donors, much more so than the mRNA expression. In genipin scaffolds, in particular, a high standard deviation was noted. This high deviation might also be linked to interference with the assay from the blue color due to the genipin cross-linking reaction.

John Wiley \& Sons, Inc.

This article is protected by copyright. All rights reserved. 
Osteogenesis and Mineralization

RCP scaffolds were able to maintain hMSCs over four weeks in growth media. Little or no change in gene expression of osteoblast markers was observed, suggesting that the hMSCs did not undergo differentiation during culture. With no intrinsic osteogenic properties, the scaffold chemistry and mechanical properties were not enough to induce an osteogenic response due to cross-linker alone. Most literature agrees that compressive moduli of at least $10 \mathrm{kPa}$ are required for spontaneous differentiation. Those studies which have demonstrated differences in osteogenic markers at less than 2 $\mathrm{kPa}$ have linked the changes to the ability of cells to exert tension in their environment, visualized via scaffold contraction [37]. Throughout the current study, there was no scaffold contraction of the RCP scaffolds. Although this precludes osteogenic properties, the lack of contraction is expected to improve the stability of the scaffolds when used in trauma sites.

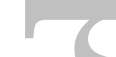

All cross-linkers tested were able to maintain osteoblast differentiation and supported a similar mineralization response. The changes in the hydration and water up-take suggest that the RCP scaffolds were chemically modified during cross-linking. Ligand density has an independent influence from mechanics on stem cell differentiation [22]. With the mechanical properties of the scaffolds remaining relatively constant, any differences in osteoblast differentiation would be expected to derive from changes in chemistry, especially changes in the number of cell ligands. The optimum density of cell adhesion ligands is different for adhesion, proliferation and migration, and above a threshold density, ligands lose their ability to bind cell receptors $[21,38]$. Even with the defined chemistry of the RCP peptide, it is difficult to calculate the density of RGD ligands presented to cells, at the scaffold surface, especially as their conformation can also affect cell recognition [39]. It was observed that the adhesion of cells in osteogenic media was significantly affected by changes in cross-linking, most likely due to interference with the ligands, with the addition of an extra chemical moiety. This did not cause a

John Wiley \& Sons, Inc.

This article is protected by copyright. All rights reserved. 
Osteogenesis and Mineralization

significant change in osteogenesis, possibly due to the relatively high density of RGD ligands compared to native gelatin. Thus, it appears that the differences in chemistry are not the main driver of hMSC differentiation in this system, suggesting that the mechanics are more strongly regulating the osteogenic properties of the scaffold.

Cross-linking is an important consideration when designing biomedical scaffolds, and is central to mechanical and chemical properties, which drive cellular response. It was demonstrated, during this study, that scaffolds from recombinant peptide could support osteogenic differentiation with a variety of cross-linkers, regardless of changes to the chemistry and hydration of the scaffolds. Given the added toxicity concerns for most chemical cross-linkers, DHT cross-linking, which does not use chemicals, is the most attractive alternative [40]. Overall, this study demonstrates the efficacy of recombinant peptides for use in bone tissue engineering, and highlights the interplay between chemical and mechanical stimuli when designing scaffolds for regenerative medicine.

\section{Conclusion}

The use of recombinant peptides in tissue engineering is increasing, due to their inherent biocompatibility and defined chemistry. For any tissue engineering construct, cross-linking is an important aspect, controlling the chemistry and mechanical properties, and thus, the biological response. Linear scaffolds from recombinant collagen type I peptide (RCP) were produced and crosslinked via several means: dehydrothermal treatment (DHT), hexamethylene diisocyanate (HMDIC), and genipin. All three cross-linking methods produced significantly different chemistry in the RCP scaffolds, while maintaining comparable mechanical properties. The interplay between chemistry and mechanics was elucidated by studying the biological response of hMSCs. It was demonstrated that cell adhesion was most affected by the scaffold chemistry, most likely due to changes in the density of available cell adhesion ligands, with cross-linking method. Regardless of cross-linker, RCP scaffolds could support the

John Wiley \& Sons, Inc.

This article is protected by copyright. All rights reserved. 
Osteogenesis and Mineralization

osteogenic differentiation and mineralization of hMSCs, demonstrating their potential use as bone repair materials.

6 Acknowledgments

The research leading to these results has received funding from the European Union Seventh

Framework Programme FP7/2007-2013 under grant agreement $n^{\circ} 607051$.

\section{Conflicts of Interest}

The recombinant peptide based on collagen type I was provided by Fujifilm Manufacturing Europe; HA van Boxtel and SGJM Kluijtmans were employed by Fujifilm.

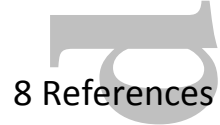

[1] Friess W. Collagen - biomaterial for drug delivery, Eur. J. Pharm. Biopharm. 1998; 45(2): 113-136.

[2] Ramshaw JAM. Biomedical applications of collagens, J. Biomed. Mater. Res., Part B 2016; 104B: 665675.

[3] Huebsch N, Arany PR, Mao AS, Shvartsman D, Ali OA, Bencherif SA, Rivera-Feliciano J, Mooney DJ. Harnessing traction-mediated manipulation of the cell-matrix interface to control stem-cell fate, Nat. Mater. 2010; 9: 518-526.

[4] Engler AJ, Sen S, Sweeney HL, Discher DE. Matrix elasticity directs stem cell lineage specification, Cell 2006; 126(4): 677-689.

[5] Kim TH, An DB, Oh SH, Kang MK, Song HH, Lee JH. Creating stiffness gradient polyvinyl alcohol hydrogel using a simple gradual freezing-thawing method to investigate stem cell differentiation behaviors, Biomaterials 2015; 40: 51-60.

[6] Murphy CM, Matsiko A, Haugh MG, Gleeson JP, O'Brien FJ. Mesenchymal stem cell fate is regulated by the composition and mechanical properties of collagen-glycosaminoglycan scaffolds, J. Mech. Behav. Biomed. Mater. 2012; 11: 53-62.

[7] Pawelec KM, Best SM, Cameron RE. Collagen: A network for regenerative medicine, J. Mater. Chem B 2016; 4(40): 6484-6496.

John Wiley \& Sons, Inc.

This article is protected by copyright. All rights reserved. 
Osteogenesis and Mineralization

[8] van Luyn MJA, van Wachem PB, Damink L, Dijkstra PJ, Feijen J, Nieuwenhuis P. Secondary cytotoxicity of cross-linked dermal sheep collagens during repeated exposure to human fibroblasts, Biomaterials 1992; 13(14): 1017-1024.

[9] Haugh MG, Jaasma MJ, O'Brien FJ. The effect of dehydrothermal treatment on the mechanical and structural properties of collagen-GAG scaffolds, J. Biomed. Mater. 2008; 89A(2): 363-369.

[10] Davidenko N, Schuster CF, Bax DV, Raynal N, Farndale RW, Best SM, Cameron RE. Control of crosslinking for tailoring collagen-based scaffolds stability and mechanics, Acta Biomater. 2015; 25: 13114.

[11] Khor E. Methods for the treatment of collagenous tissues for bioprostheses, Biomaterials 1997; 18 : 95-105.

[12] Muzzarelli RAA, Mehtedi ME, Bottegoni C, Aquili A, Gigante A. Genipin-crosslinked chitosan gels and scaffolds for tissue engineering and regeneration of cartilage and bone, Mar. Drugs 2015; 13: 73147338.

[13] Busnel JP, Morris ER, Ross-Murphy SB. Interpretation of the renaturation kinetics of gelatin solutions. Int. J. Biol. Macromol. 1989; 11: 119-125.

[14] van Boxtel H, Porous tissue scaffolds (2016) US Patent 9,440,006 B2.

[15] Pawelec KM, van Boxtel HA, Kluijtmans SGJM. Ice-templating of anisotropic structures with high permeability, Materials Science and Engineering $C$. in press.

[16] Yannas IV, Tobolsky AV. Cross-linking of gelatine by dehydration. Nature 1967; 215(5100): 509.

[17] Haugh MG, Murphy CM, McKiernan RC, Altenbuchner C, O'Brien FJ. Crosslinking and mechanical properties significantly influence cell attachment, proliferation, and migration within collagen glycosaminoglycan scaffolds. Tissue Eng., Part A 2011; 17: 1201-1208.

[18] Weadock KS, Miller EJ, Bellincampi LD, Zawadsky JP, Dunn MG. Physical crosslinking of collagen fibers: Comparison of ultraviolet irradiation and dehydrothermal treatment. J. Biomed. Mater. Res. 1995; 29: 1373-1379.

[19] De Boer AL, van Urk H, Bouwstra JB, van Asten PFTM. RGD containing recombinant gelatin (2012) US Patent 8,198,047 B2.

[20] Rosset EM, Bradshaw AD. Sparc/osteonectin in mineralized tissue, Matrix Biol. 2016; 52-54: 78-87.

[21] Benitez PL, Mascharak S, Proctor AC, Heilshorn SC. Use of protein-engineered fabrics to identify design rules for integrin ligand cluster in biomaterials, Intregr. Biol. 2016; 8: 50-61.

[22] Ye K, Wang X, Cao L, Li S, Li Z, Yu L, Ding J. Matrix stiffness and nanoscale spatial organization of celladhesive ligands direct stem cell fate, Nano Lett. 2015; 15: 4720-4729.

[23] Murphy CM, Haugh MG, O'Brien FJ. The effect of mean pore size on cell attachment, proliferation and migration in collagen-glycosaminoglycan scaffolds for bone tissue engineering, Biomaterials 2010; 31(3): 461-466.

John Wiley \& Sons, Inc.

This article is protected by copyright. All rights reserved. 
Osteogenesis and Mineralization

[24] Correia C, Bhumiratana S, Yan L-P, Oliveira AL, Gimble JM, Rockwood D, Kaplan DL, Sousa RA, Reis RL, Vunjak-Novakovic G. Development of silk-based scaffolds for tissue engineering of bone from human adipose-derived stem cells, Acta Biomater. 2012; 8: 2483-2492.

[25] Amadori S, Torricelli P, Rubini K, Fini M, Panzavolta S, Bigi A. Effect of sterilization and cross-linking on gelatin films, J. Mater. Sci.: Mater. Med. 2015; 26: 69.

[26] Poursamar SA, Lehner AN, Azami M, Ebrahimi-Barough S, Samadikuchaksaraei A, Antunes APM. The effects of cross-linkers on physical, mechanical and cytotoxic properties of gelatin sponge prepared via in-situ gas foaming method as a tissue engineering scaffold, Mater. Sci. Eng. C. 2016; 63: 1-9.

[27] Tzeranis DS, Soller EC, Buydash MC, So PTC, Yannas IV. In situ quantification of surface chemistry in porous collagen biomaterials, Ann. Biomed. Eng. 2016; 44(3): 803-815.

[28] Davidenko N, Campbell JJ, Thian ES, Watson CJ, Cameron RE. Collagen-hyaluronic acid scaffolds for adipose tissue engineering, Acta Biomater. 2010; 6(10): 3957-3968.

[29] Harley BA, Leung JH, Silva E, Gibson LJ. Mechanical characterization of collagen-glycosaminoglycan scaffolds, Acta Biomater. 2007; 3(4): 463-474.

[30] Murphy CM, Duffy GP, Schindeler A, O'Brien FJ. Effect of collagen-glycosaminoglycan scaffold pore size on matrix mineralization and cellular behavior in different cell types, J. Biomed. Mater. Res. Part $A$ 2016; 104A: 291-304.

[31] Hojo H, Ohba S, Yano F, Chung U-I. Coordination of chondrogenesis and osteogenesis by hypertrophic chondrocytes in endochondral bone development, J. Bone Miner. Metab. 2010; 28; 489502.

[32] Wang $Q$, Huang $C$, Xue $M$, Zhang X. Expression of endogenous bmp-2 in periosteal progenitor cells is essential for bone healing, Bone 2011; 48(3): 524-532.

[33] Tan S, Fang JY, Yang Z, Nimni ME, Han B. The synergetic effect of hydrogel stiffness and growth factor on osteogenic differentiation, Biomaterials 2014; 35: 5294-5306.

[34] Osyczka AM, Diefenderfer DL, Bhargave G, Leboy PS. Different effects of BMP-2 on marrow stromal cells from human and rat bone, Cells Tissues Organs 2004; 176: 109-119.

[35] Diefenderfer DL, Osyczka AM, Reilly GC, Leboy PS. BMP responsiveness in human mesenchymal stem cells, Connect. Tissue Res. 2003; 44: 305-311.

[36] Boskey AL, The organic and inorganic matrices. In: Hollinger JO, Einhorn TA, Doll BA, Sfeir C, editors. Bone Tissue Engineering. New York: CRC Press LLC; 2005, p 91-124.

[37] Koegh MB, O'Brien FJ, Daly JS. Substrate stiffness and contractile behavior modulate the functional maturation of osteoblasts on a collagen-GAG scaffold," Acta Biomater. 2010; 6: 4305-4313.

[38] Mann BK, West JL. Cell adhesion peptides alter smooth muscle cell adhesion, proliferation, migration, and matrix protein synthesis on modified surfaces and in polymer scaffolds, J. Biomed. Mater. Res. 2002; 60: 86-93.

John Wiley \& Sons, Inc.

This article is protected by copyright. All rights reserved. 
Osteogenesis and Mineralization

[39] Zhang D, Sun MB, Lee J, Abdeen AA, Kilian KA. Cell shape and the presentation of adhesion ligands guide smooth muscle myogenesis, J. Biomed. Mater. Res., Part A 2016; 104A: 1212-1220.

[40] van Luyn MJA, van Wachem PB, Olde Damink LHH, Dijkstra PJ, Feijen J, Nieuwenhuis P. Relations between in vitro cytotoxicity and crosslinked dermal sheep collagens, J. Biomed. Mater. Res. 1992; 26 : 1091-1110.
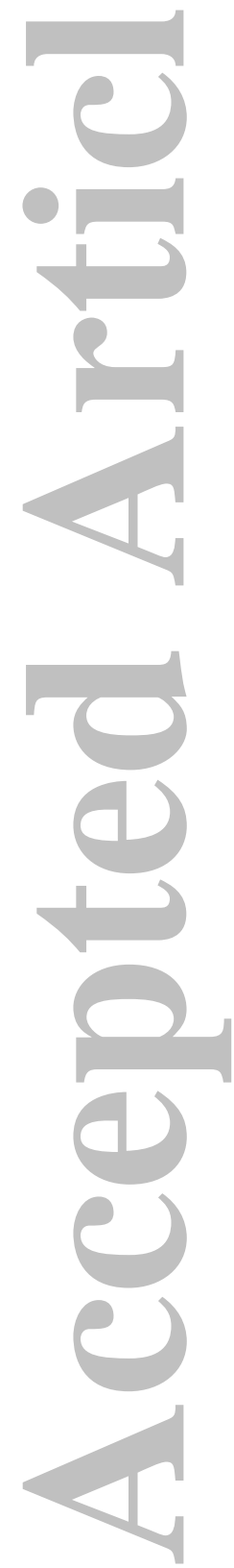

John Wiley \& Sons, Inc.

This article is protected by copyright. All rights reserved. 
Osteogenesis and Mineralization

Table 1. Scaffold properties after cross-linking ( \pm standard deviation)

Figure 1. Linear RCP scaffold created via ice-templating. Three-dimensional view via $\mu$ CT (a) entire $5 \mathrm{~mm}$ diameter scaffold (b) cross-section showing the linear pores. In the (c) transverse plane scaffolds had $400 \mu \mathrm{m}$ pores and (d) linear channels. Scale bar (c) $200 \mu \mathrm{m}$ (d) $1 \mathrm{~mm}$.

Figure 2. Human MSCs could attach and infiltrate the pores of RCP scaffolds in (a, c, e) growth media and (b, d, f) osteogenic media for all cross-linker types: (a-b) DHT, (c-d) HMDIC and (e-f) genipin. (g) Initial attachment was higher in growth media, and significantly affected by genipin cross-linking in osteogenic media. (h) Cells proliferated over 28 days with significantly greater cell number in growth media by day

7. Dashed line represents the initial number of cells seeded. *Significantly lower than all other groups ( $p$ $<0.05$ ). Scale bar (a-f): $200 \mu \mathrm{m}$.

Figure 3. Levels of (a) BMP2 and (b) RUNX2 expression differ depending on media used. mRNA expression is normalized to DHT samples in growth media at day 7 and the dashed line represents no fold-change. hMSCs were spread out on the scaffolds regardless of cross-linker (c) DHT, (d) HMDIC and (e) genipin. *Significantly greater than all osteoblast samples at day $7(p<0.05)$. \# Significantly lower than day $7(p<0.05) . * *$ Significantly greater than all other time points \& greater than all growth samples $(\mathrm{p}<0.05)$. Scale bar (c-e): $50 \mu \mathrm{m}$.

Figure 4. hMSCs produced an extracellular matrix on the RCP scaffolds. (a) Collagen type I expression was significantly enhanced in osteogenic conditions. (b, $d, f)$ In osteogenic media, cells produced a collagenous matrix on the RCP scaffold. (c, e, g) From actin staining, the cells were elongated in the direction of the linear pore walls: (b-c) DHT, (d-e) HMDIC, (f-g) genipin. White arrows indicate the

John Wiley \& Sons, Inc.

This article is protected by copyright. All rights reserved. 
Osteogenesis and Mineralization

direction of the pores. Genipin cross-linked scaffolds had a large amount of background signal in (f) and (g). The dashed line represents a fold-change of one from DHT-growth media at day 7. *Significantly greater than samples, with the same cross-linker, in growth media $(p<0.05) * *$ Significantly greater than all other time points for that cross-linker $(p<0.05)$. Scale bar $(b-g): 50 \mu \mathrm{m}$.

Figure 5. Mineralization of hMSCs on RCP scaffolds. (a) The change in hydroxyapatite content was not significantly different between cross-linking types. Markers of mineralization were up-regulated in osteogenic media regardless of cross-linker: (b) ALP, (c) osteocalcin, and (d) osteonectin. The dashed line represents a fold-change of one from DHT-growth media at day 7. *Significantly greater than samples in growth media at the same time point $(p<0.05)$. \# Significantly lower than all other time points $(p<$ 0.05).** Significantly greater than all other samples $(p<0.05)$.

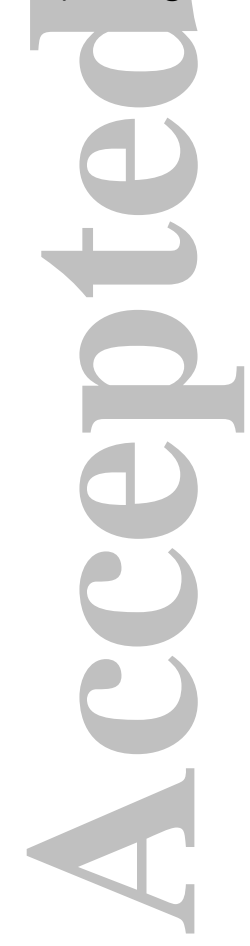

John Wiley \& Sons, Inc.

This article is protected by copyright. All rights reserved. 


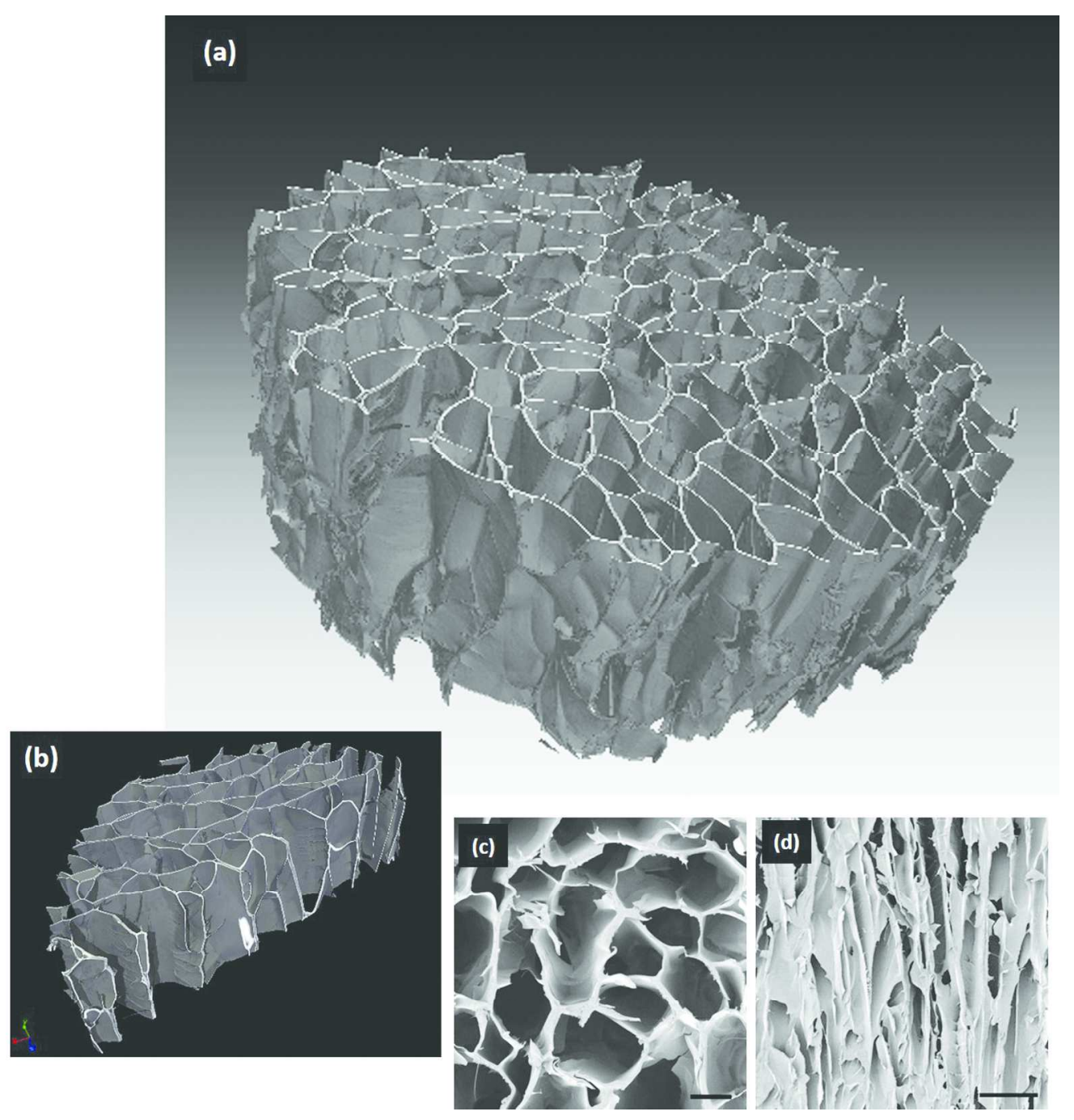

Linear RCP scaffold created via ice-templating. Three-dimensional view via $\mu \mathrm{CT}$ (a) entire $5 \mathrm{~mm}$ diameter scaffold (b) cross-section showing the linear pores. In the (c) transverse plane scaffolds had $400 \mu \mathrm{m}$ pores and (d) linear channels. Scale bar (c) $200 \mu \mathrm{m}$ (d) $1 \mathrm{~mm}$. Figure 1

$190 \times 197 \mathrm{~mm}(300 \times 300$ DPI $)$

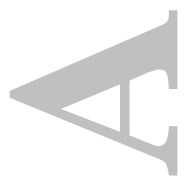

John Wiley \& Sons, Inc.

This article is protected by copyright. All rights reserved. 

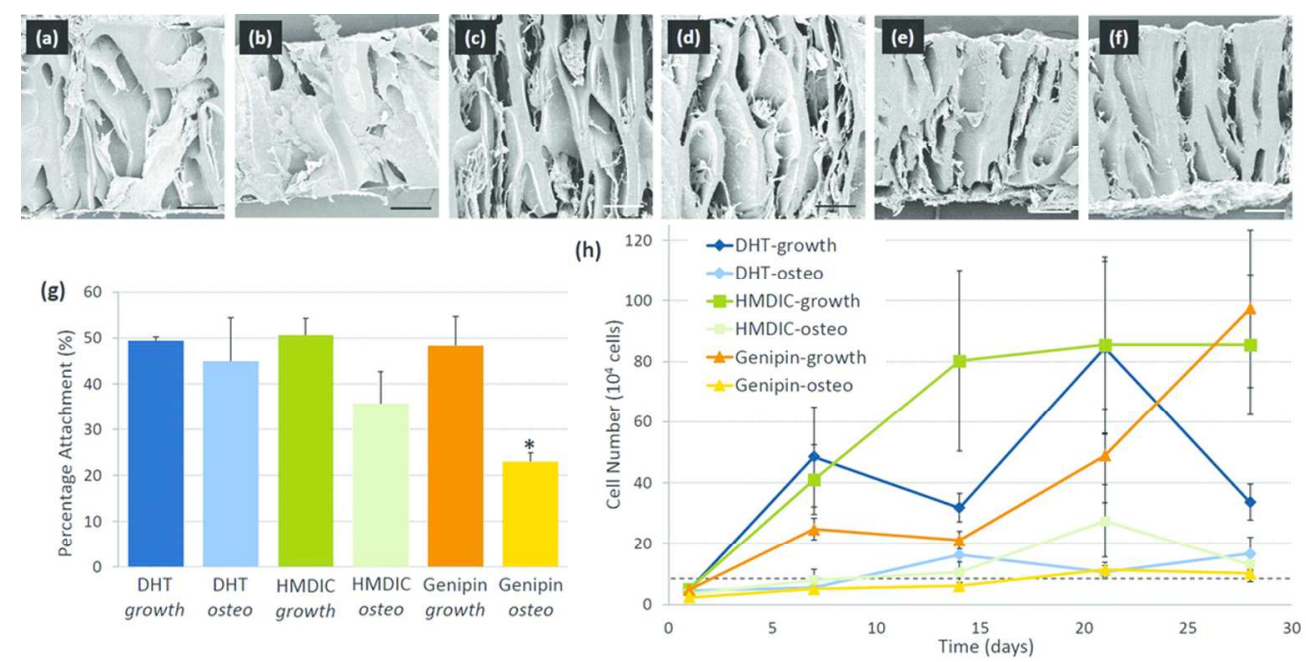

Human MSCs could attach and infiltrate the pores of RCP scaffolds in ( $a, c, e)$ growth media and (b, d, f) osteogenic media for all cross-linker types: (a-b) DHT, (c-d) HMDIC and (e-f) genipin. (g) Initial attachment was higher in growth media, and significantly affected by genipin cross-linking in osteogenic media. (h) Cells

proliferated over 28 days with significantly greater cell number in growth media by day 7 . Dashed line represents the initial number of cells seeded. *Significantly lower than all other groups $(p<0.05)$. Scale bar (a-f): $200 \mu \mathrm{m}$.

Figure 2

$96 \times 49 \mathrm{~mm}$ (300 x 300 DPI)

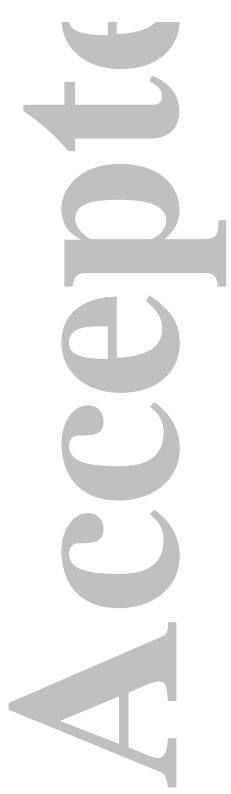

John Wiley \& Sons, Inc. 

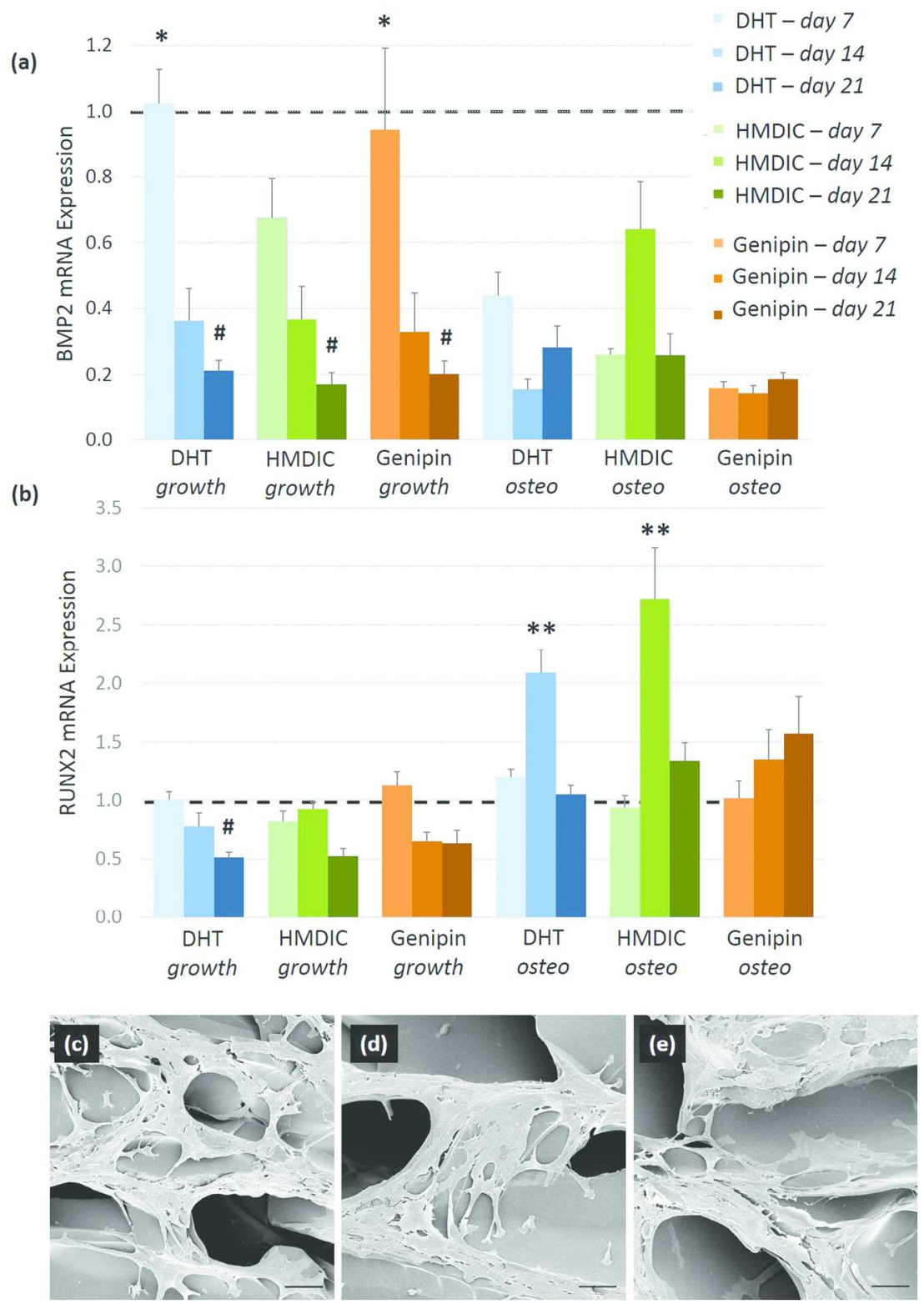

Levels of (a) BMP2 and (b) RUNX2 expression differ depending on media used. mRNA expression is normalized to DHT samples in growth media at day 7 and the dashed line represents no fold-change. hMSCs were spread out on the scaffolds regardless of cross-linker (c) DHT, (d) HMDIC and (e) genipin. *Significantly greater than all osteoblast samples at day 7 ( $p<0.05)$. \# Significantly lower than day 7 ( $p<$ $0.05)$. ** Significantly greater than all other time points \& greater than all growth samples $(p<0.05)$. Scale $\operatorname{bar}(c-e): 50 \mu \mathrm{m}$.

Figure 3

$143 \times 202 \mathrm{~mm}(300 \times 300 \mathrm{DPI})$

John Wiley \& Sons, Inc. 


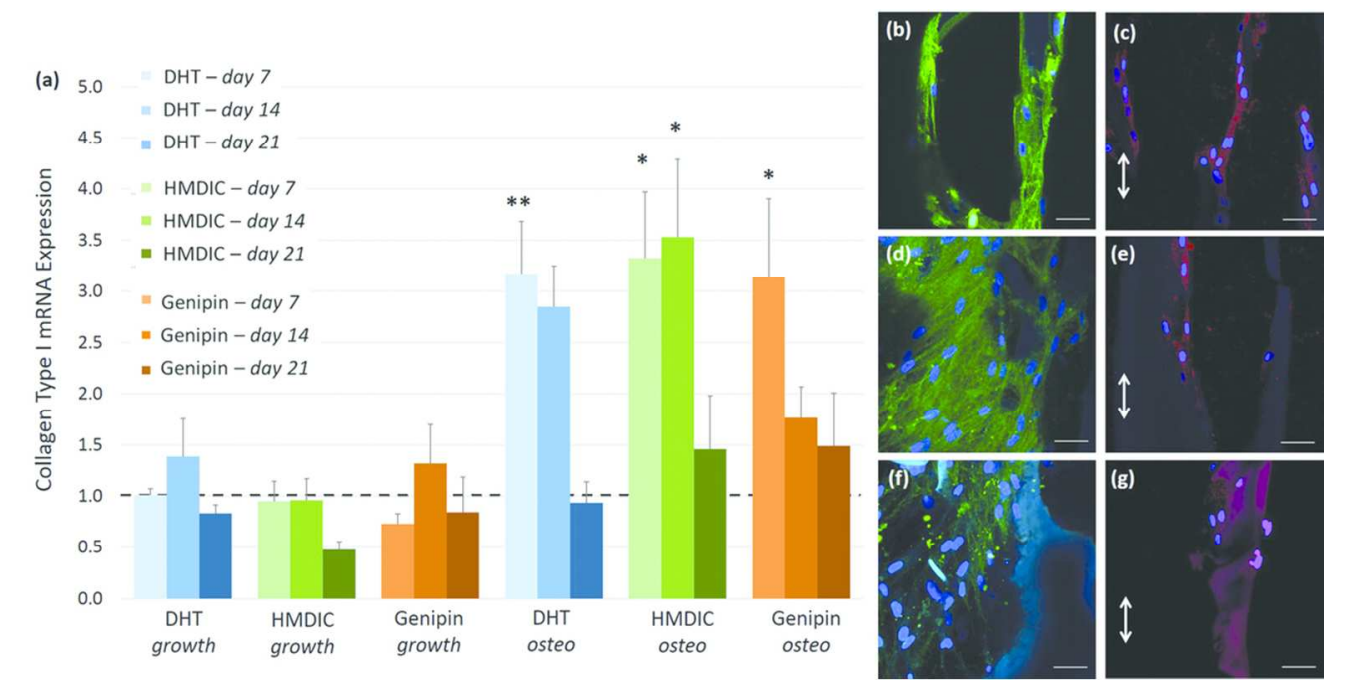

hMSCs produced an extracellular matrix on the RCP scaffolds. (a) Collagen type I expression was significantly enhanced in osteogenic conditions. ( $b, d, f$ ) In osteogenic media, cells produced a collagenous matrix on the RCP scaffold. (c, e, g) From actin staining, the cells were elongated in the direction of the linear pore walls: (b-c) DHT, (d-e) HMDIC, $(f-g)$ genipin. White arrows indicate the direction of the pores.

Genipin cross-linked scaffolds had a large amount of background signal in ( $f$ ) and $(\mathrm{g})$. The dashed line represents a fold-change of one from DHT-growth media at day 7 . *Significantly greater than samples, with the same cross-linker, in growth media $(p<0.05) * *$ Significantly greater than all other time points for that cross-linker $(p<0.05)$. Scale bar $(b-g): 50 \mu \mathrm{m}$.

Figure 4

$98 \times 50 \mathrm{~mm}(300 \times 300$ DPI)

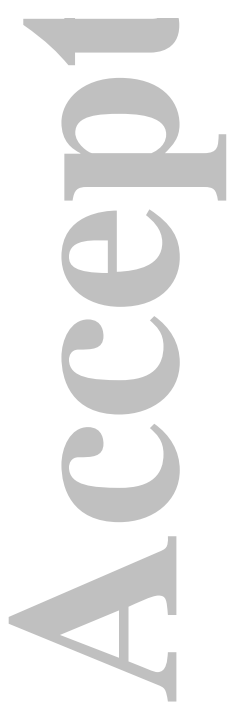

John Wiley \& Sons, Inc. 

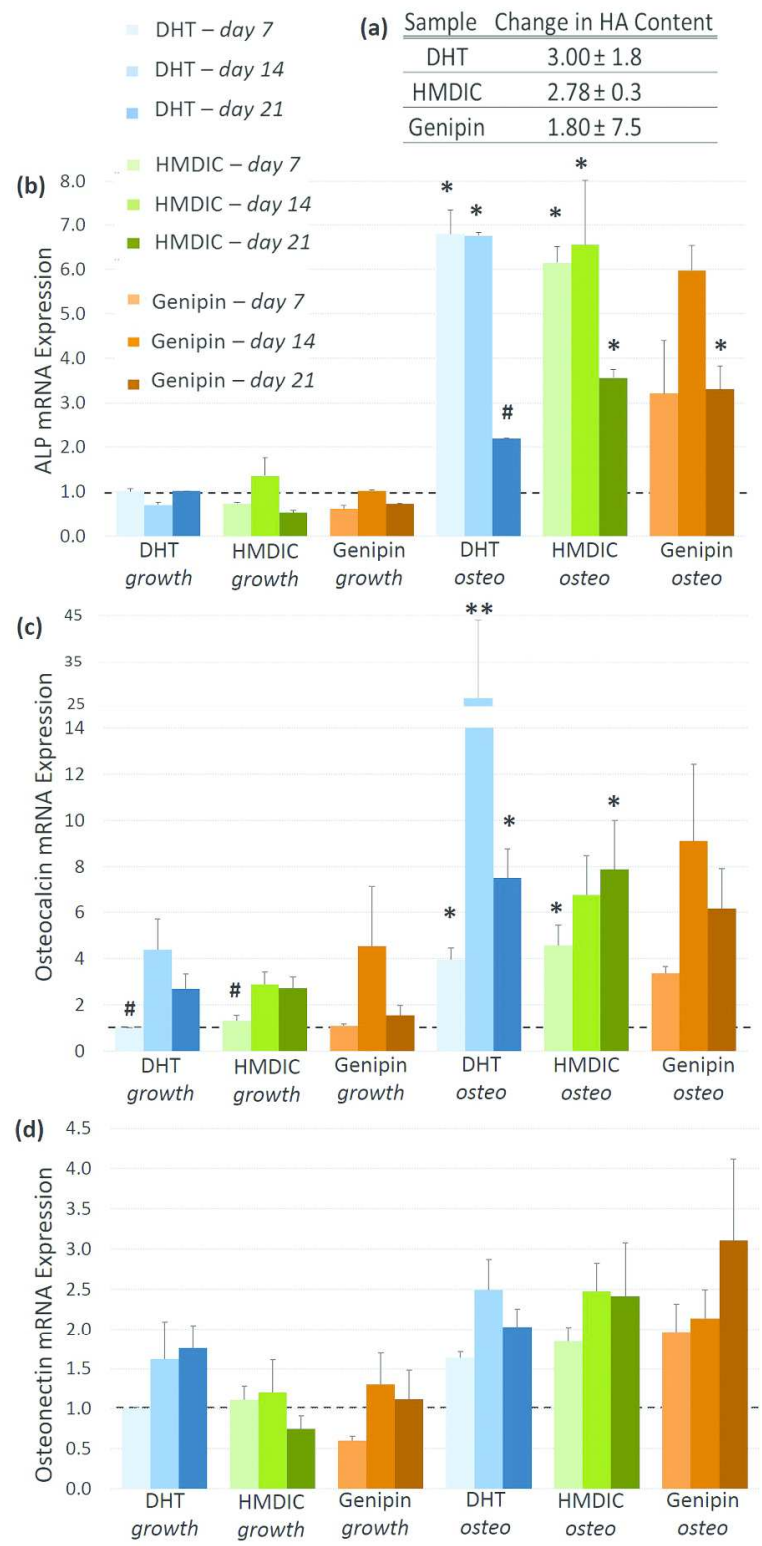

Mineralization of hMSCs on RCP scaffolds. (a) The change in hydroxyapatite content was not significantly different between cross-linking types. Markers of mineralization were up-regulated in osteogenic media regardless of cross-linker: (b) ALP, (c) osteocalcin, and (d) osteonectin. The dashed line represents a foldchange of one from DHT-growth media at day 7. *Significantly greater than samples in growth media at the same time point $(p<0.05)$. \# Significantly lower than all other time points $(p<0.05)$. ** Significantly greater than all other samples $(p<0.05)$.

Figure 5

$202 \times 403 \mathrm{~mm}(300 \times 300 \mathrm{DPI})$

John Wiley \& Sons, Inc.

This article is protected by copyright. All rights reserved. 


\begin{tabular}{cccccc} 
Cross-linker & $\begin{array}{c}\text { Cross-linking } \\
\text { Degree (\%) }\end{array}$ & $\begin{array}{c}\text { Compressive } \\
\text { Modulus } \\
(\mathbf{k P a})\end{array}$ & $\begin{array}{c}\text { Yield Stress } \\
\mathbf{( k P a )}\end{array}$ & $\begin{array}{c}\text { Overall } \\
\text { Hydration } \\
\mathbf{( \% )}\end{array}$ & $\begin{array}{c}\text { Water Up- } \\
\text { take (\%) }\end{array}$ \\
\hline DHT $)$ & $28.6 \pm 6.5$ & $1.9 \pm 0.3$ & $14.4 \pm 1.6$ & $589 \pm 162$ & $188 \pm 25$ \\
\hline HMDIC & $52.7 \pm 0.8$ & $2.5 \pm 0.6$ & $17.3 \pm 1.3$ & $754 \pm 133$ & $131 \pm 14$ \\
\hline Genipin & ------ & $2.7 \pm 0.6$ & $14.6 \pm 1.0$ & $600 \pm 249$ & $175 \pm 81$ \\
\hline
\end{tabular}

John Wiley \& Sons, Inc.

This article is protected by copyright. All rights reserved. 